\title{
ÊXODO RURAL DOS AGRICULTORES FAMILIARES NA REGIÃO DO CATONGO NO MUNICÍPIO DE ITAJUÍPE/BAHIA
}

\author{
RURAL EXODUS OF FARMERS FAMILY FROM CATONGO \\ REGION IN ITAJUÍPE/BAHIA MUNICIPALITY
}

\begin{abstract}
Maria Aparecida Nascimento Santos
Mestranda em Ciências Agrárias, pela Universidade Federal do Recôncavo da Bahia (UFRB) aparecida.santos13@bol.com.br

Sayonara Cotrim Sabioni Doutora em Educação, Professora do Instituto Federal de Educação Ciência e Tecnologia Baiano Campus Uruçuca sayonara.sabioni@ifbaiano.edu.br

Fabrício Pereira da Silva Mestre em Matemática, Professor do Instituto Federal de Educação Ciência e Tecnologia Baiano Campus Uruçuca fabrício.silva@ifbaiano.edu.br
\end{abstract}

\section{Resumo}

A região do Catongo, localizada há aproximadamente $6 \mathrm{~km}$ da cidade de Itajuípe, é composta por 15 propriedades de agricultores familiares. A região teve origem na segunda metade dos anos 30, com a descoberta do cacau Catongo, que recebeu esse nome após ser identificado na fazenda Catongo, na antiga localidade de Pirangi, atual município de Itajuípe (BA). Neste trabalho buscou-se evidenciar as particularidades do fenômeno do êxodo rural, dentre os agricultores da região do Catongo. Essa pesquisa apresentou caráter qualitativo e quantitativo. Realizou-se o Estudo de Caso, cuja coleta de dados foi realizada por meio de entrevistas estruturadas e semiestruturadas, após a identificação dos agricultores familiares remanescentes no distrito. Foi utilizada a técnica de história de vida através de encontros com os agricultores. Também foram aplicados questionários a esse público e submetidos à análise estatística dos dados quantitativos. Os resultados da pesquisa apontaram uma evasão de $80 \%$ das famílias, que abandonaram o campo em busca de emprego e melhores condições de vida na cidade, motivados pela redução do cultivo do cacau na região, pelo envelhecimento dos proprietários e pela falta de sucessores na gestão da propriedade.

Palavras-chave: Êxodo Rural. Agricultor Familiar. Desenvolvimento sócio-econômico. Identidade Camponesa. Itajuípe (BA). 


\begin{abstract}
The region of Catongo, located approximately 6 kilometers from Itajuípe City, is composed by 15 proprieties of farmers family. The region was originated from the second half of 1930s, with the discovery of Catongo cocoa, which it has gaven its name after to be identified in Catongo farm, in the old place of Pirangi, that is the actual municipality of Itajuípe (BA). The objective of this paper was to evidence the particularities of the rural exodus' phenomenon around the farmers in Catongo region. This research was made by qualitative and quantitative research method. It has done case study, which informations collect have made by structured and half structured interviews, after identification of family farmers who remaining in the district. It was utilized the technic of lives' history by meetings with the farmers.It was also applied questionnaires to this public which informations has submitted to statistical analysis of quantitative datas. The results of this research shows an evasion of $80 \%$ of families that have abandoned the countryside looking for jobs and a better life situation in the city. That is why there is a reduction of the cocoa's cultivation in the region, plus the aging of the farm's owners and deficiency of successors in the management of the propriety.
\end{abstract}

Keywords: Rural Exodus. Family Farming. Economic-social development. Itajuípe (BA).

\title{
Introdução
}

O êxodo rural tem sido um dos problemas mais frequentes nas regiões brasileiras, motivado por diversos fatores. Um dos principais motivos, na região Litoral Sul da Bahia, na década de 80 , foi a crise da produção cacaueira, gerada pela introdução da vassourade-bruxa (Moniliophtora perniciosa), doença que acomete o cacaueiro. Muitos municípios sentiram os impactos econômicos e sociais, provocados pela redução de até $100 \%$ da produção de cacau nas fazendas da região. Com a baixa dos preços do produto no exterior, o grande declínio da produção afetou especialmente, os trabalhadores camponeses não proprietários de terras, demitidos em massa e expulsos das propriedades rurais.

A região do Catongo, pertencente ao município de Itajuípe, localizado no Litoral Sul da Bahia, atingida pelos impactos dessa crise cacaueira, foi acometida nas últimas décadas pelo êxodo rural, intensificando a saída do homem do campo para os centros urbanos. Muitos agricultores foram forçados a se mudarem para a cidade, devido à falta de condições favoráveis para a permanência em suas propriedades. Como a produção de cacau, nesta localidade, já era pequena, por conta da supressão das áreas de terras, pelos 
grandes fazendeiros em volta, com a chegada desta doença, a produção foi reduzida drasticamente.

Sem condições para dispor de um suporte técnico capaz de orientá-los a aproveitar as potencialidades da região, muitos destes agricultores familiares decidiram deixar suas terras. Com todos estes entraves, a agricultura familiar na localidade, perdeu sua essência e o distrito de Catongo registrou, nas últimas décadas, um declínio populacional bastante acentuado. Neste trabalho, o universo pesquisado foi de 15 (quinze) famílias de agricultores familiares, correspondente a $100 \%$ (cem por cento) dos entrevistados, distribuídas em 15 propriedades rurais, localizadas na referida região, no município de Itajuípe, Litoral Sul da Bahia. A opção por utilizar todo o universo populacional coaduna com o proposto por Martins e Domingues (2017) posto que esses autores apontam que, populações com potencialidades para serem pesquisadas em sua totalidade, isso deve ser executado, devido à facilidade de coleta e execução da pesquisa.

Para melhor delimitação na coleta de dados, utilizou-se um marco no tempo, que compreendia os anos de início da crise da produção cacaueira, maior incentivador do êxodo rural na região, ao ano em que foi realizada a pesquisa. Esse marco compreendeu os anos de 1991 a 2016. Com isso analisou-se a saída da população do meio rural durante os 25 (vinte e cinco) anos de enfrentamento dos problemas que acometeram a produção agrícola.

A pesquisa apresentou caráter qualitativo e quantitativo, onde foram aplicados questionários estruturados e semiestruturados, com análise estatística dos dados, com auxílio do Software Excel. Os questionários continham questões sobre: idade, sexo, quantidade de pessoas por sexo que moravam na propriedade antes do êxodo, no ano de 1991; escolaridade, renda familiar, local de trabalho, condições de moradia, quantidade de pessoas que deixaram a propriedade rural, o local (cidade) para onde migraram, os motivos que levaram essas pessoas mudarem-se, se houve mudança nas condições de vida dos que se mudaram, situação atual da propriedade rural e como era essa propriedade no passado.

A coleta de dados foi realizada por meio de documentos municipais: livros e arquivos, encontrados na biblioteca do município; estatísticas oficiais coletadas em sites institucionais: Instituto Brasileiro de Geografia e Estatística (IBGE), Superintendência de Estudos Econômicos e Sociais da Bahia (SEI), constituindo-se essas como fontes 
secundárias. Ainda foi realizada uma pesquisa de campo, com aplicação de questionários, encontros com os agricultores, percurso por toda a região estudada, constituindo-se essa como fonte primária.

Algumas informações sobre a Região do Catongo foram obtidas através de relatos dos proprietários mais antigos, uma vez que não foram encontrados trabalhos de pesquisa na localidade, nem documentos que relatassem a história desses agricultores.

Utilizou-se, ainda, a técnica história de vida, permitindo que cada indivíduo fizesse uma retrospecção dos anos anteriores e expusesse seus sentimentos de pertença, as suas raízes e cultura, e relatasse suas experiências passadas na época em que a região ora analisada, era considerada, por eles, um local agradável para se viver. Essa técnica é uma ferramenta muito importante em pesquisas sociais. De acordo com Becker (1994) a história de vida de alguém tem mais valor quando contada pela própria pessoa, sendo esta narradora e interprete das experiências por elas vividas.

Diante do exposto, o presente trabalho buscou analisar os significados e impactos do êxodo rural para os moradores da região do Catongo, em especial os elementos impulsionadores da migração dentre os sujeitos que atuam na agricultura familiar. Além disso, centramos estudos nos aspectos que podem potencialmente propiciar a permanência dos agricultores familiares em suas propriedades.

\section{O cenário do êxodo rural no Brasil}

A população brasileira tem sua origem no meio rural, onde se formou e se encontra as primeiras raízes da organização social do nosso país. Podendo-se afirmar que, "a sociedade brasileira surge no meio rural; e é neste que ela se forma, se organiza, se esteia, tornando o estabelecimento rural o centro de nossa formação" (DIÉGUES JUNIOR, 1973, p.151).

Seguindo por este viés, percebe-se a grande importância cultural e histórica que este meio representa para a conservação da identidade camponesa das comunidades advindas das áreas rurais. Contudo, esta identidade vem se perdendo ao longo dos anos, graças a transição pela qual o país vem passando nas últimas décadas, especialmente pela industrialização, que de forma direta favoreceu o esvaziamento rural. 
Com isso, comunidades rurais vêm se deslocando constantemente para os centros urbanos em busca de melhores condições de vida. O que tem gerado um enorme problema de organização social, ao mesmo tempo, que provoca uma grande desordem na organização espacial. Conti (2012, p.11) revela que, "a partir de 1950, a saída de indivíduos e famílias das áreas rurais em direção aos centros urbanos sofreu uma aceleração no país, envolvendo milhões de pessoas todos os anos".

De acordo com a literatura, a definição mais elementar para o fenômeno do "êxodo rural" é a saída de pessoas do campo para as cidades visando uma vida melhor. "Esta "vida melhor" é entendida, na maioria das vezes, como oportunidades de trabalho remunerado; segurança familiar; busca de qualidade do ensino e serviços básicos" (DINIZ, 2011, p.01).

Hartwig (2007, p.3) define o movimento de migração campo/cidade como "deslocamento de famílias de agricultores, principalmente os jovens, para os centros urbanos". Conforme Alves; Silva e Marra (2011, p.81) "as pessoas migram porque acham que vão melhorar de vida no novo destino escolhido", enquanto Conti (2012, p.28) expõe que "o próprio termo êxodo rural já traz em sua raiz a designação de movimento ou saída de uma situação de vida, geralmente difícil, para uma situação que seja mais favorável para se viver, mesmo que esta seja apenas hipotética".

O êxodo rural é bastante expressivo em várias regiões brasileiras, tendo como causa diversos fatores que impulsionam esse deslocamento constante de comunidades do campo rumo aos centros urbanos. De acordo com Conti (2012, p.29), “o Nordeste, onde o mercado urbano se tornou expansivamente atrativo, foi uma das regiões que contribuiu de forma mais significativa para o êxodo rural, nos anos de 1970". Nesse mesmo ano, Gaspar (1970, p.128) publica seu trabalho, onde apresenta a principal causa do êxodo rural nessa região:

[...] de fato, o êxodo rural resulta, sobretudo da má distribuição e aproveitamento das terras: a existência de latifúndios concentrando, sem aproveitamento, imensas extensões de terras nas mãos de uns poucos; por outro lado, há uma proliferação de minifúndios, cuja rentabilidade econômica é insuficiente para manter uma família. Os latifúndios brasileiros chegam a atingir 500 a 1000 ha., enquanto uma significante porção dos minifúndios não chega a 20 ha.

E ainda, Conti, (2012, p.11) relata que, 
[...] a diminuição da mão de obra, a redução da produtividade de algumas áreas de agricultura familiar e as dificuldades de sucessão familiar no meio rural podem estar entre os principais fatores que aceleram o êxodo rural nas regiões brasileiras.

A intensificação destas migrações nas zonas rurais brasileiras tem gerado uma grande preocupação, pois acarreta vários problemas sociais e organizacionais. Segundo Ramalho e Neto (2007, p.345) "o aumento das migrações e o rápido adensamento populacional no meio urbano contribuíram para o aumento da pobreza, criminalidade, desemprego, e congestionamento no acesso aos serviços públicos”. Faria (2009) afirma que, no Brasil, o êxodo rural contribuiu para o crescimento desordenado dos centros urbanos, gerando um verdadeiro caos social.

Por resultante de um desenvolvimento socioeconômico excludente, adotado pelo Estado brasileiro, "as áreas rurais vivenciam situações de pobreza extrema, com 2,8 milhões de pessoas vivendo em moradias precárias, ocupando áreas de risco; o que tem acarretado sérios problemas sociais e ambientais” (WANDERLEY, 2009, p.70).

Conforme Malassis (1973, p.104) “de um modo geral, a intensificação do êxodo rural provoca a "superurbanização", e transforma o desemprego rural em desemprego urbano com suas sequelas".

Como causa desse fenômeno populacional de saída em massa da população rural para as cidades outros autores apontam a modernização da agricultura como um dos fatores mais relevantes. Segundo Schneider e Fialho (2000 p. 126), a modernização da agricultura na região Sul, foi a grande causa do êxodo rural nessa região. Segundo eles, “desde a primeira metade do século XX, o desenvolvimento da agricultura no Rio Grande do Sul se encontrava entre os mais modernos no Brasil". "Tal projeto foi imposto ao conjunto da sociedade, sob o argumento de que seria o portador do progresso para todos" (CASTRO, 2015, p. 03). Contudo, teve como principal resultado, a subordinação da agricultura à indústria, formando o que se denomina complexo agroindustrial.

De acordo com Wanderley, (2009, p.71) "O processo de modernização excludente resultou na expulsão da grande maioria dos trabalhadores, não proprietários de suas terras". Tais acontecimentos, somados a pouca atenção que o setor agrícola familiar recebe pelo estado brasileiro, a situação se tornou ainda mais preocupante, pois diferentemente da situação clássica de outros países, a agricultura familiar no Brasil 
sempre ocupou espaços deixados pela grande agricultura. "E devido a esse caráter marginal, vem encontrando, dificuldades para programar um sistema produtivo sustentável a longo prazo" (JUNQUEIRA; LIMA, 2008, p.161).

Dentro deste contexto, a agricultura familiar ficou à margem, deixando ao pequeno agricultor a opção de buscar uma vida melhor nos centros urbanos, tendo desta forma, suas perspectivas de vida frustradas.

Atualmente alguns municípios brasileiros vêm tentando reverter a situação, investindo nas comunidades rurais, no entanto, o triste quadro do êxodo rural no país, ainda está longe de estabilizar. Afinal, os incentivos e políticas públicas para agricultura familiar são na prática burocráticos, tornando-se inacessíveis à maioria dos agricultores.

\section{Caracterização e histórico do município de Itajuípe}

O município de Itajuípe, situado na área central da região cacaueira, com aproximadamente 21.081 habitantes, apresenta densidade demográfica de 77,46 hab./ $/ \mathrm{km}^{2}$ (IBGE, 2010). O município tem suas origens na Capitania Hereditária de São Jorge dos Ilhéus (PIRES, 2001, p.12). Banhado pelo rio Almada, sua principal rodovia de acesso é a BR 101.

O bioma predominante na região é a Mata Atlântica que abriga uma vasta diversidade biológica. Dentro da Mata, os agricultores cultivam o cacau sombreado, conhecido como "Cacau cabruca", devido ao hábito de "brocar" a floresta (ralear a mata através da poda de algumas árvores), a fim de abrir clareiras para a entrada de luz solar no cacaueiro. "Essa forma de cultivo do cacau possibilitou a conservação de remanescentes da Mata Atlântica" (LOBÃO, 2007, p.9).

A economia do município de Itajuípe tem sua principal riqueza na exploração da lavoura cacaueira, apesar das diversas crises, que tem passado a cultura dessa lavoura. "No passado, parte da renda municipal era sustentada por suas 704 (setecentos e quatro) propriedades agrícolas" (PIRES, 2001, p.15). "Na década de 1970, o município alcançou produção média anual de 640.000 (seiscentos e quarenta mil) arrobas de cacau sendo, à época, o terceiro município produtor de cacau do Brasil” (PIRES, 2001, p.16).

Por apresentar essa característica favorável ao cultivo do cacau, o município apresenta um grande potencial para se desenvolver economicamente, principalmente com 
a exploração deste produto. Além de apresentar características para o cultivo de produtos como: frutas, hortaliças, entre outros. No entanto, a insuficiência das políticas públicas voltadas para o meio rural, base econômica da cidade de Itajuípe, impossibilita esse desenvolvimento.

As políticas públicas de assistência às comunidades rurais são insuficientes, chegando a ser inexistente em algumas situações, como por exemplo, o Programa de Aquisição de Alimentos (PAA), segundo informações da Secretaria de Agricultura do município, encontra-se inativo. Isso pode contribuir para a não comercialização da produção, tornando uma agricultura de subsistência, deixando o agricultor sem garantia de uma renda, que possibilite o desenvolvimento socioeconômico dessas comunidades.

A falta de assistência técnica aos agricultores também é outro fator notável. Segundo informações, obtidas por meio de entrevistas com alguns agricultores da região, os poucos que permaneceram no campo, não dispõem de técnicos que os auxiliem na produção agrícola. A falta de uma assistência impossibilita a implementação de novas tecnologias de produção e um consequente declínio na produtividade. Dessa forma, os agricultores, não conseguem produzir o suficiente para o sustento de suas famílias e vivem hoje em situação difícil. Esse foi um dos prováveis motivos que impulsionou a migração para os centros urbanos.

Diante desses acontecimentos a economia estagnou, surgiram novas áreas periféricas sem pavimentação, sem saneamento básico e com grande quantidade de moradias inadequadas, que oferecem riscos às famílias habitantes; além dos problemas da população no acesso aos serviços públicos de saúde, educação, entre outros.

Houve um aumento no índice de desemprego, uma vez que o comércio local, pequeno, não comporta a grande demanda de pessoas desempregadas, que vivem na cidade, somada, às que saíram do campo, sem nenhuma qualificação técnica, tornandose ainda mais difícil, o ingresso desses migrados no mercado de trabalho na área urbana.

Atualmente, no município de Itajuípe, a população rural encontra-se em situação de abandono, o que aumentou expressivamente o êxodo nessas regiões, reflexo da grande mobilidade campo/cidade das populações rurais para os centros urbanos. 


\section{Caracterização e histórico da região do Catongo.}

Figura 1- Município de Itajuípe e suas áreas rurais - Região do Catongo.

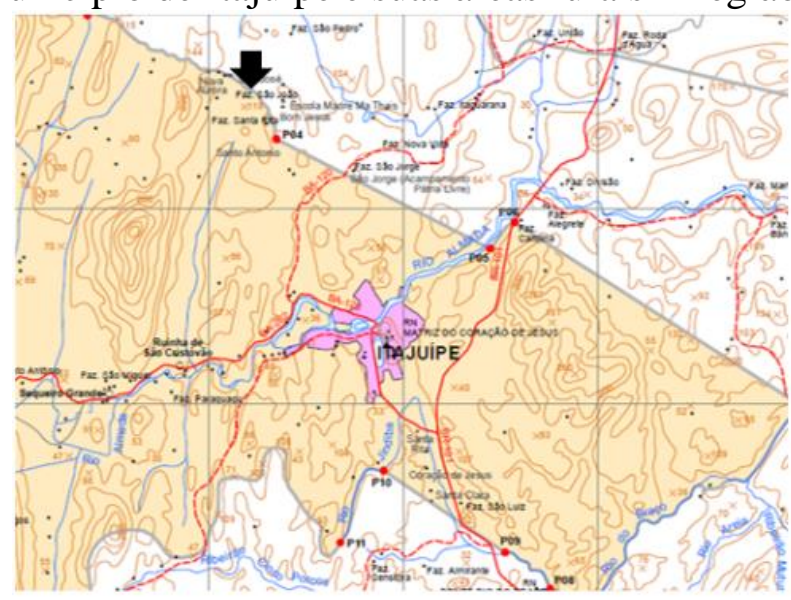

Fonte: SUPERINTENDÊNCIA DE ECONÔMICOS E SOCIAIS DA BAHIA (SEI), 2014.

A região do Catongo, cuja localização geográfica está a -14.633658 latitude Sul, -39.394281 longitude Oeste, localizada, há aproximadamente $6 \mathrm{~km}$ da cidade de Itajuípe, é composta por 15 propriedades de agricultores familiares. Nos aspectos sociais, a maioria das moradias são casas de taipas (fabricadas em material de argila e madeira), as propriedades são desprovidas de saneamento básico, os esgotos são lançados a céu aberto ou fossas rústicas e o lixo queimado. A fonte de água utilizada são cisternas e alguns córregos que passam na região. Atualmente, das 15 propriedades existentes na localidade, a maioria encontra-se abandonada, enquanto seus donos residem na cidade de Itajuípe, principalmente nos bairros mais pobres do município.

Segundo relatos dos agricultores, foi concluído, na região, um projeto da Caixa Econômica Federal: Programa de Nacional de Habitação Rural (PNHR), que contemplou apenas 33,3\% destas familiais. Os contemplados já tiveram suas moradias construídas em materiais de bloco e cimento.

Da mesma forma aconteceu com a chegada de um projeto do governo federal: "Luz para Todos", que atendeu apenas parte das propriedades, enquanto outras se encontram sem energia elétrica. Mesmo, com esses benefícios para alguns, não houve mudança na situação de abandono dessas propriedades, pois, seus donos residem na cidade e as visitam, esporadicamente. 
Ainda, segundo relatos de moradores antigos desta região, no passado, todas as propriedades eram habitadas por famílias numerosas e todos os filhos de agricultores moravam no campo e trabalhavam na agricultura, auxiliando seus pais na produção agrícola.

Em datas festivas como São João e Natal, os moradores se reuniam para realizarem festas, e se divertiam, dançavam e bebiam a noite inteira. As festas eram bem organizadas e todos bastante unidos.

As famílias se reuniam, quase todas as noites, em volta de fogueiras, onde os mais idosos, contavam várias histórias para os mais novos. Às vezes, alguns vizinhos participavam daquelas reuniões e ali, ficavam até altas horas.

Para diversão dos jovens, costumavam fazer torneios de futebol, com direito a troféus e algumas recompensas como: porcos, vacas, dinheiro, entre outros. Para eles, era uma grande diversão.

As moças preferiam se divertir com cantigas de roda. Quase todo final de semana, havia "forró pé de serra" na região, para quem gostava de dançar, a diversão era garantida!

O som ficava por conta de um sanfoneiro, que tocava até o dia amanhecer. Pelo que se percebe em seus relatos, a cultura desse povo era algo importante para eles e faziam questão de conservar.

Na produção agrícola, nesta época, as principais culturas eram o cacau, cultivado em sistema cabruca, a mandioca, banana e outros produtos. A grande maioria deles produzia farinha de mandioca e seus derivados como: beiju, tapioca, goma, puba, entre outros. Todas as propriedades tinham uma boa produtividade, pois o solo era bastante fértil.

As famílias eram compostas por muitos membros: filhos e filhas; genros e noras; netos e netas; cunhados, entre outros e a renda familiar gerada pela agricultura e pela criação de alguns animais domésticos, como: galinhas, porcos, algumas cabeças de gado, era suficiente para alimentar toda a família.

Com o passar dos anos, a terra passou a produzir menos, já não gerava a mesma receita de antes. Como um dos principais produtos cultivados era a mandioca, em sistema de monocultura ou consorciada com milho, feijão e abóbora, contribuiu para o esgotamento do solo, explorado intensivamente, devido a não existência de outras áreas para o cultivo. 
Os agricultores disseram que não tinham o costume de adubar a terra e utilizavam o sistema de queima para a limpeza das áreas. A partir de então, começaram a se preocupar com o futuro dos filhos, naquela propriedade improdutiva. Junto a isto, somouse a falta de escolas para as crianças e jovens, que eram obrigados a caminhar quilômetros para estudar na cidade.

Diante desses entraves, para manterem os filhos estudando, algumas mães resolveram se mudar para o centro urbano, enquanto o esposo continuava no campo, garantido o sustento da família, que agora se dividia, com parte, na cidade e o pai sozinho no campo, longe de sua família. Dessa forma, alguns deles resolveram morar com a esposa e os filhos na cidade e visitavam esporadicamente a propriedade rural.

Atualmente a economia da região encontra-se estagnada, que pode ser atribuído a vários fatores, incluindo a dificuldade de acesso as políticas de incentivo à produção agrícola, a exemplo do Programa Nacional de Fortalecimento da Agricultura Familiar (Pronaf), com oferta de crédito ao produtor rural, para investir na lavoura, possibilitando o retorno às suas propriedades, e o resgate da sua cultura, que lhe conferia uma identidade camponesa, hoje, totalmente abandonada.

\section{Fatores de influência no êxodo rural na região do Catongo no município de Itajuípe.}

O município de Itajuípe, situado na área central da região cacaueira, conta com 21.081 habitantes (IBGE, 2010). Esse município possui uma área de aproximadamente $270.752 \mathrm{~km}^{2}$ de extensão o que nos fornece uma densidade demográfica de 77,46 hab. $/ \mathrm{km}^{2}$.

Do total de 21.081 habitantes, 4.242 correspondia a população rural de todas as regiões do município de Itajuípe, em 2010. Em 1991, essa população era mais do dobro, com aproximadamente, 8.959 habitantes, residentes na área rural. No ano 2000, a população rural teve um decréscimo, em comparação ao ano de 1991, chegando a um total de 6.388 habitantes. Em 20 anos, houve uma evasão de aproximadamente 53\% da população rural para a cidade nas várias regiões do município de Itajuípe.

Nesse contexto de êxodo acelerado, também se insere a região do Catongo. Segundo as estatísticas, a evasão dos habitantes desta localidade chegou a um percentual de $80 \%$ das famílias que abandonaram o campo em busca de emprego e melhores 
condições de vida na cidade, uma vez que, o campo não oferecia condições para a permanência destes agentes nas propriedades rurais.

Conforme resultados obtidos através dos questionários aplicados, antes da crise cacaueira, ocorrida entre os anos de 1980 e 1992, com a chegada da vassoura-de-bruxa na região; a população do Catongo era em média de 4,4 homens/propriedade e 3,4 mulheres/propriedade em 1991 (TABELA 1). Verificamos também que $75 \%$ das propriedades possuíam 6 ou mais moradores, demonstrando uma tendência, no final da na década de 80 e início da década de 90, da existência de famílias numerosas. Enquanto existia em 1991 a presença de 15 famílias na região do Catongo em 2016 esse número se reduz a existência de 3 famílias, apresentando uma média de 2,67 membros por grupo familiar. Esse número em 1991 era de 7,80 pessoas por grupo familiar, os dados atuais representam uma redução de $65,82 \%$ demonstrando o quanto o êxodo na região do Catongo foi acentuado. As medidas descritivas que estão sintetizadas na Tabela 1, revelam uma situação pior ou no mínimo igual à de outras regiões do país no que toca o êxodo rural no ano de 1991. Os estudos realizados por Maia e Buainain (2015), mostram que a média da relação pessoas/propriedade no Catongo estava muito distante da realidade nacional, que naquele ano foi de 4,7 habitante por propriedade rural, enquanto que no Catongo essa média foi de 4,4 para homens e 3,4 para mulheres, perfazendo um total de 7,8 habitantes por propriedade.

Tabela 1: Medidas descritivas das variáveis da quantidade de pessoas/propriedade na região do Catongo em Itajuípe no ano de 1991.

Quantidade de Pessoas/ propriedade em 1991

\begin{tabular}{lcc}
\cline { 2 - 3 } Medidas descritivas & Homens & Mulheres \\
\hline Média & 4,40 & 3,40 \\
Mediana & 5,00 & 3,00 \\
1 quartil & 2,50 & 3,00 \\
3 quartil & 6,00 & 4,00 \\
Mínimo & 1,00 & 1,00 \\
Máximo & 8,00 & 6,00 \\
Amplitude total & 7,00 & 5,00 \\
Desvio padrão & 2,29 & 1,30 \\
Coeficiente de Variação (\%) & 52,05 & 38,24 \\
\hline n= & 88,24 & 64,9
\end{tabular}


Autores como Camarano e Abramovay (1998) confirmam a importância da análise de dados do senso demográfico quanto a percepção da importância do êxodo rural brasileiro. Nesse mesmo trabalho os autores ainda mostram que a predominância de homens em relação as moças no campo era uma realidade desde o ano de 1971, fato esse que é observado na região do Catongo.

Nessa época, essas comunidades sofriam o grande impacto da queda na produção cacaueira, no entanto, continuavam na área rural na tentativa de superar os prejuízos causados pela praga da vassoura-de-bruxa. Com o passar dos anos, sem tecnologias adequadas e suficientes para potencializar a produção do cacau, iniciou-se a migração destas famílias para os centros urbanos, não só, na região do Catongo, como também, nas demais regiões rurais do município. Resultando na diminuição da quantidade de pessoas residentes no campo.

Vinte e cinco anos depois, a população da região do Catongo encontra-se em uma situação preocupante. Atualmente, das famílias entrevistadas, apenas $20 \%$ residem no campo. A média de pessoas/propriedade agora é de 2 homens e 0,67 mulheres (TABELA 2). As demais famílias, ainda possuem propriedades na localidade, no entanto, residem na cidade e visitam suas fazendas esporadicamente. Ao confrontar esses dados com a realidade nacional, nota-se grande discrepância se comparados com os dados do ano de 2010, visto que a nível nacional a média de ocupação de pessoas por domicílio foi de 3,6 segundo Maia e Buainain (2015), enquanto no Catongo essa ocupação em 2016 foi de apenas 2,67 habitantes por propriedade (TABELA 2). Nesse mesmo sentido há uma prevalência de maior quantidade homens, conforme observado por Camarano e Abramovay (1998).

$\mathrm{Na}$ região estudada, houve mudança dos moradores em todas as propriedades investigadas, sendo estes filhos e filhas desses agricultores, que migraram para trabalhar e estudar na cidade. Na maioria dos casos, o próprio agricultor e sua esposa também se mudaram; tendo como preferência de destino as cidades de Itajuípe, Rio de Janeiro, São Paulo. Alguns migraram para Ilhéus e São José da Vitória. 
Tabela 2: Medidas descritivas das variáveis da quantidade de pessoas na região do Catongo em Itajuípe no ano de 2016.

Quantidade de Pessoas/ propriedade em 2016

\begin{tabular}{lcc}
\cline { 2 - 3 } Medidas descritivas & Homens & Mulheres \\
\hline Média & 2,00 & 0,67 \\
Mediana & 1,00 & 0,00 \\
1 quartil & 1,00 & 0,00 \\
3 quartil & 2,50 & 1,00 \\
Mínimo & 1,00 & 0,00 \\
Máximo & 4,00 & 2,00 \\
Amplitude total & 3,00 & 2,00 \\
Desvio padrão & 1,73 & 1,15 \\
Coeficiente de Variação (\%) & 86,50 & 171,64 \\
\hline $\mathrm{n}=$ & 102,73 & 178,46
\end{tabular}

Por ser Itajuípe a cidade mais próxima, verificamos que 53\% escolheram-na como preferência de destino. Constatamos que, a mesma não oferece muitas oportunidades de trabalho, uma vez que, as possibilidades de emprego se concentram no comércio local, que é pequeno, e na indústria, possui apenas uma fábrica, Penalty, de artigos desportivos. Possivelmente, a busca por emprego não foi um fator prioritário para os que migraram para a cidade de Itajuípe, considerando que o município não dispõe de um mercado de trabalho que comporte a demanda de emprego pela população. Sendo assim, grande parte dos residentes em Itajuípe migraram motivados por facilidade de acesso a serviços básicos como: escolas, hospitais, segurança, entre outros.

Entretanto a hipótese de que na cidade de Itajuípe estes agricultores teriam melhores condições de vida não se concretizou. Tendo em vista que, a oportunidade de emprego constitui-se um fator essencial, quando se pensa em melhoria de vida e desenvolvimento socioeconômico destas famílias. Isso na maioria das vezes não é observado por estas pessoas, pois acreditam que podem residir na cidade e continuarem trabalhando no campo, no entanto as dificuldades são ainda maiores, pois fora de suas propriedades ocorre uma perda de identidade, comprometendo ainda mais o empenho produtivo do camponês, uma vez que não se sente mais parte integrante daquele ecossistema. Além das dificuldades enfrentadas no acesso às propriedades, pela distância e o péssimo estado das estradas vicinais das zonas rurais. Por esta razão, o índice de desemprego nas cidades aumenta, enquanto as propriedades rurais são esvaziadas, expandindo as áreas periféricas e o número de pessoas que vivem em situação insalubre. 
Tais fatos, foram confirmados quando investigamos a situação de moradia destas pessoas na cidade, verificou-se que todas as casas são próprias, já quitadas, adquiridas a preços acessíveis, na época em que a propriedade rural gerava uma boa renda. Possuem energia elétrica e água canalizada, recursos que, na área rural não se encontravam até certo tempo. Porém, apenas $17 \%$ dessas moradias na cidade estão localizadas em bairros com saneamento básico.

Segundo Faria (2009), o êxodo rural contribuiu para o crescimento desordenado dos centros urbanos e gerou um verdadeiro caos social. E como resultado desse caos, “cerca de 2,8 milhões de pessoas no Brasil, vivem em moradias sem água canalizada, banheiro, sanitário e luz elétrica” (WANDERLEY, 2009, p.70). Para Ramalho e Neto (2007, p.345) "o próprio aumento das migrações e o rápido adensamento populacional no meio urbano contribuíram para o acirramento da pobreza, desemprego, criminalidade e congestionamento no acesso aos serviços públicos".

Outro indicador do êxodo rural na região do Catongo foi o envelhecimento da população. Com média de 64 anos, e capacidade laboral reduzida, muitas famílias não dispunham de mão de obra para a execução das atividades agropecuárias. Rangel e Tonella (2013, p.88) afirmam "está havendo uma escassez de trabalhadores, uma vez que os migrados, nesses mais de 20 anos de crise cacaueira, estão idosos e seus filhos adquiriram outras perspectivas de vida, para além de serem trabalhadores do cacau".

Nesse caso em questão, muitos filhos de agricultores saíram do campo em busca de estudo e emprego na cidade, revelando a necessidade que esses jovens possuem de tornarem-se independentes. Enquanto isso, seus pais, com idade avançada e força laboral diminuída, encontram-se, hoje, aposentados e vivem com até um salário mínimo, residindo também no centro urbano.

A quantidade dos proprietários já aposentados, cerca de 60\%, indica o envelhecimento da população da região, o que intensificou o fenômeno do êxodo. Outra influência da aposentadoria na intensificação do êxodo rural foi à possibilidade de uma renda mensal fixa, deixando esses agricultores mais seguros quanto ao sustento da família. A renda advinda da propriedade rural se tornou uma fonte secundária e complementar da renda familiar, ao ponto que deixou de ser necessária para estes agricultores. 
Para eles, se tornou mais viável, viver com até um salário mínimo na cidade, mesmo em condições insalubres, em áreas periféricas, sem saneamento básico. Segundo uma proprietária entrevistada, "mesmo não tendo uma moradia confortável e sua renda mensal ser insuficiente para suprir as despesas com alimentação, contas e remédios, a vida na cidade, comparada com a área rural, é bem melhor, pela facilidade de acesso a hospitais, supermercados e transporte. $\mathrm{Na}$ área rural tais serviços são escassos e muitos deles inexistentes". A entrevistada acrescentou ainda, que, "estando ela idosa, com a saúde frágil, é necessário morar na cidade, pois no caso de uma emergência o acesso à propriedade rural é bem mais difícil".

Outra informação interessante é que excluindo os idosos aposentados, $20 \%$ destes agricultores encontram-se desempregados, 13\% são autônomos e trabalham informalmente na agricultura e apenas 7\%, trabalha com carteira assinada. Esses dados revelam a dificuldade destas pessoas em conseguirem emprego na cidade e como o sonho de uma vida melhor acaba frustrado.

Na produção entre os anos de 1991-2000, as quinze propriedades dos agricultores familiares da Região do Catongo tinham como principais culturas: cacau, mandioca, banana. Alguns proprietários cultivavam coco, fruta-pão, cana-de-açúcar, abacaxi e criação de galinha caipira, porcos, algumas cabeças de gado. A mandioca era beneficiada, e comercializados seus derivados: beiju, tapioca, goma, puba, entre outros. Todos esses produtos eram utilizados para o consumo próprio e o excedente, vendido em feiras livres na cidade de Itajuípe.

Atualmente, $73 \%$ dessas propriedades são utilizadas por seus proprietários, para produção de cacau sem manejo; outros agricultores não vão mais à propriedade, deixando-a aos cuidados de um dos filhos e apenas $20 \%$ dos entrevistados ainda moram na região. Duas das propriedades encontradas foram vendidas.

Outro problema encontrado entre as pessoas entrevistadas é o alto índice de analfabetismo. Dos proprietários entrevistados 46,6\% são analfabetos, 46,6\% possui ensino fundamental incompleto nas séries inicias da $1^{\mathrm{a}}$ a $4^{\mathrm{a}}$ e assinam apenas o nome. Apenas 6,6\% concluíram o ensino médio.

$\mathrm{O}$ alto índice de analfabetismo interfere significativamente na sobrevivência desses agricultores na área urbana, pois o mercado de trabalho está cada vez mais exigente e procura mão de obra qualificada. Sem qualificação e escolaridade, esses indivíduos 
ficam às margens da política desenvolvimentista dos setores produtivos. Com isso, houve um aumento drástico, no número de favelas e na criminalidade no país. De acordo com pesquisas do IBGE (2010), o Brasil apresenta 6.329 favelas em todo o país, sendo que grande parte da população vive em moradias irregulares nos grandes centros como São Paulo, Rio de Janeiro, Belém Salvador, Recife e São Luís. Uma das principais causas dessa grande favelização é o êxodo rural.

Embora, continuem vivendo na cidade, muitos dos entrevistados afirmaram sentir saudade do campo e demonstraram o interesse de voltar a viver em suas propriedades. Porém, a idade avançada de alguns, já não os permitem viver na área rural, pela dificuldade de acesso a localidade em casos de emergência, devido ao péssimo estado de manutenção das estradas vicinais.

Como podemos notar o êxodo rural significou para esses atores sociais: perda de identidade, por meio do afastamento de suas raízes e cultura; desemprego para uma parcela dos migrados e o aumento da população urbana da cidade de Itajuípe, com o surgimento de novos bairros e áreas de riscos sendo ocupadas.

Como se pode notar, os resultados alcançados neste trabalho, não diferem muito de situações encontradas em outras localidades do Brasil, assemelhando-se também nas causas desse fenômeno como: problemas econômicos e sociais, domínio das terras agrícolas por latifundiários, dificuldade no acesso a serviços básicos: escolas, hospitais; envelhecimento da população rural, entre outros (PRADO, 1995; WANDERLEY, 2000; MARTIN, 2005).

Como solução para diminuir o êxodo rural Diniz (2011, p.01) apresenta algumas soluções. Segundo o autor é preciso incentivar outros municípios do Brasil a seguirem o exemplo do que foi feito no município de Ariquemes em Rondônia, promovendo:

\footnotetext{
- O desenvolvimento de agroindústrias visando agregar valores aos produtos agrícolas, garantindo remuneração e geração de renda às famílias rurais; - A propagação nas Escolas Polos da ideia de assegurar aos jovens rurais conhecimentos acadêmicos teóricos e práticos que atendam não só a grade curricular do Ministério da Educação e Cultura (MEC), mas também às necessidades do campo;

- A presença do Policiamento na zona rural, atuando preventivamente no combate as infrações;

- As manutenções e aberturas de estradas vicinais permitindo, tanto nos períodos de secas como nos de chuvas, o deslocamento das pessoas e o escoamento da produção;
} 


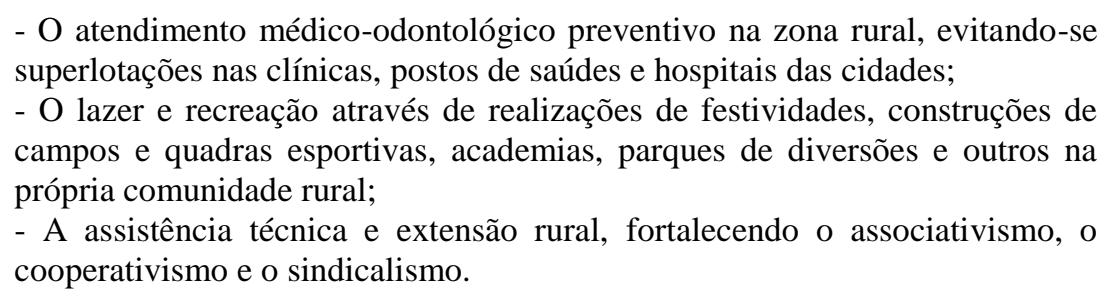

De acordo com o autor, tais soluções diminuirão o êxodo rural e as pessoas viverão bem melhor e com qualidade de vida na área rural. Tal exemplo mostra, que a mudança será possível apenas com a adoção de mecanismos no sentido de diminuir o êxodo rural e promover a permanência do camponês em suas terras.

\section{Conclusão}

Com base nos resultados deste trabalho, as condições de vida dos agricultores da região do Catongo foi o principal motivo que os impulsionaram a migrar, acarretando muitos outros problemas que intensificou ainda mais esse movimento entre as famílias entrevistadas. Dentre os problemas identificamos: a falta de condições favoráveis à permanência desses agricultores no campo, causada inicialmente pela crise cacaueira, com a queda dos preços do produto no mercado internacional e a chegada da vassourade-bruxa. Em seguida, na tentativa de superar a crise cacaueira, investiram na cultura da mandioca e outros produtos, que também entraram em declínio anos depois, esgotando a fertilidade dos solos da região.

Outro fator que intensificou o êxodo nesta região foi o envelhecimento da população, em especial dos proprietários, que ao se aposentar, tiveram uma maior segurança em permanecerem na cidade, uma vez que, passaram a ter um salário mensal fixo, não dependendo diretamente a renda advinda da agricultura.

Logo após vem o alto índice de analfabetismo entre os entrevistados. Esse fator dificultou o ingresso no mercado de trabalho, resultando em um percentual elevado de desempregados, outros tiveram que trabalhar informalmente na agricultura, e um percentual muito pequeno conseguiram trabalhar com carteira de trabalho assinada.

No tocante a identificação sobre os destinos de migração desses agricultores, encontramos grande parte na cidade de Itajuípe, outros migraram para cidade de São 
Paulo e Rio de Janeiro, em busca de emprego. Alguns deles tiveram como preferência de destino as cidades de Ilhéus e São José da Vitória.

Segundo as estatísticas, a evasão das famílias, desta localidade foi bastante acentuado, revelando uma diminuição preocupante na população rural dessa localidade. Esse cenário traz impactos diretos para a agricultura familiar da região, visto a mesma ser hoje no país a principal responsável pela segurança alimentar da população.

Diante dos resultados, percebemos que a migração para esses sujeitos teve um significado diferente do esperado. O êxodo rural significou para esses agentes: perda de identidade, desemprego rural e urbano para uma parcela dos migrados, aumento da população urbana da cidade de Itajuípe, com o surgimento de novos bairros e áreas de riscos sendo ocupadas.

Tais problemas só poderão ser resolvidos por meio de políticas de incentivos ao desenvolvimento socioeconômico das comunidades rurais, promovendo à volta do homem do campo para suas propriedades, oferecendo-lhes condições de desenvolver sua produção agrícola através de subsídios, por meio das políticas de crédito rural, para que esses atores sociais vivam de forma digna.

\section{Referências}

ALVES, Eliseu. SOUZA, Geraldo. MARRA, Renner. Êxodo e sua contribuição à urbanização de 1950 a 2010.Ano XX - N ${ }^{o} 2$ - Abr/Maio/Jun, p. 80-88, 2011.

BECKER, H. Métodos de Pesquisa em Ciências Sociais. 2a. ed. São Paulo: Hucitec. 1994.

CAMARANO, A. A.; ABRAMOVAY, R. Êxodo rural, envelhecimento e masculinização no Brasil: panorama dos últimos cinquenta anos. Revista Brasileira de Estudos de População, Rio de Janeiro: Associação Brasileira de Estudos Populacionais, v. 15, n. 2, p. 45-66, jul./dez. 1998.

CASTRO, Luis Felipe Perdigão de. A agricultura familiar e seus valores: perspectivas para um outro desenvolvimento. In: Âmbito Jurídico, Rio Grande, XVIII, n. 142, nov 2015.

CONTI, Daniele Taíse. Estudo dos fatores de influência na migração rural/urbana no município de Orizontina. $80 \mathrm{f}$. Trabalho de Conclusão (Bacharel em Ciências Econômicas). Faculdade Horizontina - FAHOR, Horizontina - Rio Grande do Sul, 2012. 
DIÉGUES JUNIOR, Manuel. Populações Rurais Brasileiras: vida rural e mudança social. Ed. Nacional. São Paulo. 1973. 293p.p.151-164.

DINIZ, João. O que fazer para diminuir o êxodo rural?. Areia-PB, 02 de abril de 2011. Disponível em:

http://www.emater.ro.gov.br/siteemater/arquivos/publicacoes/13042011110759.pdf. Acesso em: 07 Mai. 2016.

FARIA, Caroline. Êxodo rural. 2009. Disponível em:http://www.infoescola.com/geografia/exodo-rural. Acesso em: 13 Fev.2016.

GASPAR, Luciano Mota. Migrações rurais e crescimento urbano. Rev. C. Sociais. São Paulo. VoL. I N.o 1. p. 124-135. Janeiro 1970.

HARTWIG, Marisa. Migração Campo Cidade: trajetórias de vida, trabalho e escolarização de jovens trabalhadores. Disponível em:

http://coral.ufsm.br/sifedocregional/images/Anais/Eixo\%2001/Marisa\%20Hartwig.pdf. Acesso em: 21 Out.2015.

IBGE. Instituto Brasileiro de Geografia e Estatística. Censo Demográfico 2010. Disponível em:

http://www.cidades.ibge.gov.br/xtras/perfil.php?lang=\&codmun=291550\&search=bahia |itajuipe. Acesso em: 23. Out. 2015.

JUNQUEIRA, Clarissa. LIMA, Jandir. Políticas públicas para a agricultura familiar no Brasil.Ciências Sociais e Humanas, Londrina, v. 37, n. 1, p.159-176, jul/dez. 2008.

LOBÃO, Dan Érico Vieira Petit. Agroecossistema Cacaueiro da Bahia: Cacau Cabruca e Fragmentos Florestais na Conservação de Espécies Arbóreas. 108 f. Tese (Doutorado em Produção Vegetal). Faculdade de Ciências Agrárias e Veterinárias Unesp, Jaboticabal - São Paulo, 2007.

MAIA, Alexandre Gori e BUAINAIN, Antonio Marcio, «O novo mapa da população rural brasileira », Confins [Online] 25 |2015. Disponível em: http://journals.openedition.org/confins/10548; DOI: 10.4000/confins. 10548. Acesso em 19. Mai.2019.

MALASSIS, Louis. Educação e Desenvolvimento Rural: vida rural e mudança social. Ed. Nacional. São Paulo. 1973. 292p.p.99-115.

MARTIN, Gilberto Berguio; CORDONI JÚNIOR, Luiz; BASTOS, Yara Gerber Lima. Aspectos demográficos do processo de envelhecimento populacional em cidade do sul do Brasil. Epidemiologia e Serviços de Saúde, v. 14, n. 3, p. 85-90, 2005.

MARTINS, Gilberto de Andrade e DOMINGUES, Osmar. Estatística geral e aplicada. 6. ed. São Paulo: Atlas, 2017. 
PIRES, Vicente. Memórias Históricas de Itajuípe. Ed. Agora. Itabuna. Bahia. Brasil. 2001. 52p.

PRADO, Adonia Antunes. Ruralismo pedagógico no Brasil do Estado Novo. Estudos sociedade e agricultura, v. 4, p. 5-27, 1995.

RAMALHO, Hilton Martins de Brito. SILVEIRA NETO, Raul da Mota. Capital humano e retorno à migração: o caso da migração rural-urbana no nordeste do Brasil. Revista Econômica do Nordeste, Fortaleza, v. 38, nº 3, p.343-364, jul-set. 2007.

RANGEL, Maria Cristina. TONELLA, Celene. A crise da região cacaueira do sul da Bahia/Brasil e a reconstrução da identidade dos cacauicultores em contexto de adversidades. Revista do Programa de Pós-Graduação em Geografia. Maringá, v. 5, n. 1, p. 77-101, 2013.

SEI. Superintendência de Estudos Econômicos e Sociais da Bahia. Informações municipais. Disponível em:

http://www.sei.ba.gov.br/index.php?option=com_wrapper\&view=wrapper\&Itemid=266 Acesso em: 21 Jul. 2015.

SEI. Superintendência de Estudos Econômicos e Sociais da Bahia. Divisão Políticaadministrativa do Estado da Bahia. Versão Maio, 2014.

SCHNEIDER, Sergio; FIALHO, Marco Antônio Verardi. Pobreza rural, dese- quilíbrios regionais e desenvolvimento agrário no Rio Grande do Sul. Teoria e Evidência Econômica. Passo Fundo - RS, v. 8, n. 15, p. 117-149, 2000.

WANDERLEY, Maria de N.B. A valorização da agricultura familiar e a reivindicação da ruralidade no Brasil. Desenvolvimento e Meio Ambiente, v. 2, 2000.

WANDERLEY, Maria. O mundo rural brasileiro: acesso a bens e serviços de integração campo-cidade. Estud.soc.agric.. Rio de Janeiro, vol. 17, no. 1. p. 60-85. Setembro, 2009. 